\title{
Errors during Paediatric Cardiac Anaesthesia: Reporting and Learning
}

\author{
Mohammad Hamid, Mohammad Irfan Akhtar, Fauzia Nasim Minai, Amar Lal Gangwani
}

Department of Anaesthesiology, Aga Khan University, Karachi, Pakistan.

Email: mohammad.hamid@aku.edu

Received August 20 $0^{\text {th }}, 2013$; revised September 21 ${ }^{\text {st }}, 2013$; accepted October $2^{\text {nd }}, 2013$

Copyright (C) 2013 Mohammad Hamid et al. This is an open access article distributed under the Creative Commons Attribution License, which permits unrestricted use, distribution, and reproduction in any medium, provided the original work is properly cited.

\begin{abstract}
Incident reporting is a reliable quality assurance tool, frequently used in anaesthesia to identify errors. It was introduced in anaesthesia by Cooper in 1978 and since then several institutions have adopted this system to find adverse events and near misses. We think that the incident reporting would be more beneficial for prolonged and technically complex procedures like paediatric cardiac surgery. Methods: All paediatric CHD patients scheduled for cardiac surgery were included in this audit. Thoracic and general surgery patients were excluded. Any event in preoperative area, induction room, operating room and during transfer to cardiac ICU was documented in a predesigned proforma by resident/consultant. This proforma included information regarding demographics, the type and severity and responsible factors for the event. Results: 134 patients were included in this two and half years audit. 88 patients were male $(65.7 \%)$ and 46 $(34.3 \%)$ were female. The age of the patients ranged from one day to 15 years. Total 105 incidents were noticed in 61 patients. 46 incidents were declared as major events which were potentially serious while 59 events were of minor nature. Cuffed endotracheal tube was used in $73 \%$ patients. The majority of events occurred in the pre-bypass period. Most of the incidents were related to cardiovascular system (73\%), followed by pharmacological incidents. Human factors (74\%) were mainly responsible for the incidents. Conclusion: Incident reporting is a reliable and feasible method of improving quality care in developing countries. It helps in identifying areas which need improvement and helps in developing guidelines to improve safety.
\end{abstract}

Keywords: Paediatric; Congenital Heart Surgery; Anaesthesia; Errors

\section{Introduction}

Incident reporting is a reliable quality assurance tool, frequently used in anaesthesia to identify errors. It was introduced in anaesthesia by Cooper [1] in 1978 and since then several departments have used voluntary incident reporting to find adverse events and near misses.

Incident reporting is probably more important for prolonged and technically complex procedures like paediatric cardiac surgery which requires longer hospital stay. Adverse event is a major concern during the management of paediatric cardiac surgery patients due to the presence of intracardiac defect, severity of disease and complexity of surgery in these patients. Errors in medical management can occur at several steps including pre bypass, bypass, post bypass period, during the transfer of patient to CICU and in the CICU but the possibility of untoward incident is higher in OR [2] than ICU or wards.
Incident reporting is a well established and an effective way of identifying these events. Incident reporting not only helps in identification of actual adverse events but also near misses and no harm events can be identified. The severity of the incident affects the outcome of the patient, ranging from transient damage to full recovery or increasing length of hospital stay and in the worst cases death.

We started incident reporting in paediatric congenital heart disease (CHD) surgery patients with the aim of improving the quality of care. Critical Incident for this audit is defined as "An incident that affected or could have affected, if uncorrected, the safety of patient during the period of care. Our aim of this audit was to prospectively compile the critical incidents in paediatric cardiac anaesthesia, review the root cause, analyze and provide recommendations to improve patient safety. 


\section{Method}

All paediatric CHD patients who were scheduled for cardiac surgery were included in this audit. Thoracic and general surgery patients were excluded. Any event in preoperative area, induction room, operating room and during transfer to cardiac ICU was documented in a predesigned proforma by resident/consultant responsible for immediate care of patient at that time. Detailed description of incident and suggestions for improvement were recorded in the predesigned form. This proforma included information regarding demographics, the type and severity and responsible factors for the event.

All statistical analysis was performed using statistical package of social science version 19 (SPSS Inc. Chicago, IL). Number of single and multiple incidents of each patient were counted and presented as " $\mathrm{m}$ ". Frequency and percentages were used to summarize incident characteristics and other categorical variables as well as differences in proportion were evaluated by chi-square test. Median with IQR was estimated for age of patients. Factors, suggestions, prevention and outcome of incident were also presented in term of frequency and percentage. $\mathrm{p} \leq 0.05$ was considered as significant.

\section{Results}

134 patients were included in this audit of two and half year period. 88 patients were male $(65.7 \%)$ and 46 (34.3\%) were female (Table 1). The age of the patients ranged from one day to 15 years with median age of 21 months. Total 105 incidents were noticed in 61 patients. An average of 0.78 anaesthesia related incidents occurred in each case. The person reporting the incident scored the level of harm. 46 incidents were declared as major events which were potentially serious while 59 events were of minor nature and not expected to cause serious consequences.

Cuffed endotracheal tube was used in $73 \%$ patients. The majority of events occurred in the pre-bypass period. Most of the incidents were related to cardiovascular system $(73 \%)$, followed by pharmacological incidents (Table 2). Difficult intravenous and invasive line access was noticed in 45 patients leading to delay in starting the surgery and potential for hypothermia. One patient temporarily developed lower limb ischemia due to femoral arterial spasm after femoral arterial line placement.

Human factors $(74 \%)$ were mainly responsible for the incidents and main suggestion was to provide better training and education $(52.5 \%)$ of the residents and medical officers. These incidents led to major physiological impairment in $6 \%$ and morbidity in $4 \%$ of patients. There was no significant association between age of the patients and timing of the event (p-value: 0.517 ). We were also unable to find any association between gender and
Table 1. Descriptive information of the patients and incidents.

\begin{tabular}{|c|c|c|}
\hline Detailed & $\mathbf{n}$ & Percentage \\
\hline Total number of patients (n) & 134 & - \\
\hline Total number of incidents (m) & 105 & - \\
\hline Incidence of incidents in patients & 61 & $45.5 \%$ \\
\hline - $\quad$ Multiple incidents $(\geq 2)$ & 32 & $52.5 \%$ \\
\hline - Single incident & 29 & $47.5 \%$ \\
\hline \multicolumn{3}{|l|}{ Gender } \\
\hline - Male & 88 & $65.7 \%$ \\
\hline - Female & 46 & $34.3 \%$ \\
\hline \multicolumn{3}{|l|}{ Mode of Admission ${ }^{*}$} \\
\hline - Elective & 122 & $91 \%$ \\
\hline - Emergency & 06 & $4.5 \%$ \\
\hline \multicolumn{3}{|l|}{ Age (months) } \\
\hline Median (IQR) & $21(65)$ & \\
\hline Maximum Age & 15 Years & \\
\hline Minimum Age & 3.9 Days & \\
\hline \multicolumn{3}{|l|}{ Timing of the event $(n=61)$} \\
\hline - Pre bypass & 43 & $70.5 \%$ \\
\hline - Post bypass & 18 & $29.5 \%$ \\
\hline \multicolumn{3}{|l|}{ ETT } \\
\hline - Cuffed & 98 & $73.1 \%$ \\
\hline - Un cuffed & 19 & $14.2 \%$ \\
\hline - Not mentioned & 17 & $12.2 \%$ \\
\hline Major Incidence & 31 & $58.8 \%$ \\
\hline Minor Incidence & 30 & $49.72 \%$ \\
\hline
\end{tabular}

Mode of admission of 6 patients are missing.

severity of incidence. High number of minor incidences were noticed during pre-bypass period (Table 3) while major incidences were more common during and after bypass with p-value of 0.034 .

\section{Discussion}

Errors in medicine are among the 10 leading causes of death [3]. Incident reporting can play a major role in developing strategies for improving patient safety. Factors responsible for the incidents must be identified which can be a system failure or human factor. The reason should be identified and recommendations made in a large group. These audits help in improving the standards of care and leads to the development of new policies and 
Table 2. Pediatric congenital heart critical incident $(\mathrm{m}=$ 105).

\begin{tabular}{|c|c|c|}
\hline Incidents & Count (m) & Percentage \\
\hline Intubation Related Incidents $(\mathrm{n}=\mathbf{2})$ & 02 & $1.9 \%$ \\
\hline - Unanticipated difficult intubation & 01 & $0.95 \%$ \\
\hline - Bronchospasm & 01 & $0.95 \%$ \\
\hline ETT and Circuit Incident $(n=3)$ & 03 & $2.8 \%$ \\
\hline - Circuit Disconnection & 02 & $1.9 \%$ \\
\hline - Other: Leak tube change to large size tube & 01 & $0.95 \%$ \\
\hline Pulmonary Incidents $(\mathrm{n}=3)$ & 05 & $4.7 \%$ \\
\hline - Hypoxemia & 02 & $1.9 \%$ \\
\hline - Hypercapnia & 01 & $0.95 \%$ \\
\hline \multicolumn{3}{|l|}{ - Other: } \\
\hline Left Lung Collapse & 01 & $0.95 \%$ \\
\hline Wrong route (Intravenous Sildenafil given & 01 & $0.95 \%$ \\
\hline \multicolumn{3}{|l|}{ Orally during CPB time, no reaction seen) } \\
\hline Cardiac Incidents $(\mathrm{n}=\mathbf{1 1})$ & 18 & $17.1 \%$ \\
\hline - Cardiac Arrest/CPR & 4 & $3.8 \%$ \\
\hline - Bradycardia & 5 & $4.7 \%$ \\
\hline - Tachycardia & 1 & $0.95 \%$ \\
\hline - Hypotension & 6 & $5.7 \%$ \\
\hline - Hypertension & 1 & $0.95 \%$ \\
\hline - Others & 1 & $0.95 \%$ \\
\hline Pharmacological Incidents $(n=9)$ & 09 & $8.5 \%$ \\
\hline \multicolumn{3}{|l|}{ - Under dosage } \\
\hline - Over dosage & 01 & $0.95 \%$ \\
\hline - Other: (2 not describe) & 04 & $3.8 \%$ \\
\hline \multicolumn{3}{|l|}{ Ceftazidine diluted in vancomycin bag } \\
\hline recognized after dilution not administerd & 01 & $0.95 \%$ \\
\hline \multicolumn{3}{|l|}{ Muscle relaxant (Pavulon) changes color after } \\
\hline Dilution so discarded & 01 & $0.95 \%$ \\
\hline Drug Administration at wrong time & 01 & $0.95 \%$ \\
\hline Unnecessary boluses of phenylephephrine & 01 & $0.95 \%$ \\
\hline $\begin{array}{l}\mathrm{CVP} / \mathrm{IV} / \mathrm{A} \text {-line insertion } \\
\text { related Incidents }(\mathrm{n}=38)\end{array}$ & 59 & $56.1 \%$ \\
\hline - Carotid puncture & 13 & $12.3 \%$ \\
\hline - Hematoma Neck & 01 & $0.95 \%$ \\
\hline - Difficult IV & 14 & $13.3 \%$ \\
\hline - Difficult A-line & 16 & $15.2 \%$ \\
\hline
\end{tabular}

\section{Continued}

\begin{tabular}{|c|c|c|}
\hline - Difficult CVP & 15 & $14.2 \%$ \\
\hline Monitoring Incidents $(\mathrm{n}=5)$ & 05 & $4.7 \%$ \\
\hline - $\quad$ NIBP & 01 & $0.95 \%$ \\
\hline - Art-Line & 03 & $2.8 \%$ \\
\hline - LA Line & 01 & $0.95 \%$ \\
\hline Vascular Incidents $(n=2)$ & 02 & $1.9 \%$ \\
\hline - Extravasation & 02 & $1.9 \%$ \\
\hline Miscellaneous $(n=2)$ & 02 & $1.9 \%$ \\
\hline \multicolumn{3}{|l|}{ - Other: } \\
\hline $\begin{array}{l}\text { Blood products not available till patients } \\
\text { went on by pass }\end{array}$ & 02 & 1.9 \\
\hline
\end{tabular}

Values are number and percentage.

Table 3. Association with time of event with Major/Minor incidence.

\begin{tabular}{cccc}
\hline \multirow{2}{*}{ Time of Event } & \multicolumn{2}{c}{ Incident } & p-value \\
\cline { 2 - 3 } & Major Incidence & Minor Incidence & \\
\hline Pre bypass & $16(57.1 \%)$ & $27(81.8 \%)$ & 0.034 \\
Post bypass & $12(42.9 \%)$ & $6(18.2 \%)$ & \\
Total & 28 & 33 & \\
\hline
\end{tabular}

processes to prevent adverse events in the future [4]. One such initiative was taken by Society of Cardiovascular Anesthesia called FOCUS [5] (Flawless Operative Cardiovascular Unified System) to identify hazards during cardiac surgery and then develop interventions.

Voluntary and anonymous reporting is helpful in documenting an event without fear and retribution. At the same time disadvantage of this type of reporting is that the importance of event reporting particularly minor incidents, is some how reduced as you are not making it mandatory to report. Under reporting of incidents is also a factor and there are multiple reasons for that.

Largest self reported incidents occurred in cardiac surgery to date [6]. Cardiac surgery is associated with higher incidence of adverse events (12.3\%) when compared with all surgical admissions (3\%). Type of incidents and harmful incidents differ in OR when compared with non OR environment. Bates et al. [7] in a prospective study determined that $25 \%$ of deaths among cardiothoracic surgery patients are avoidable. $21 \%$ of incidents occurred in the OR in cardiac surgery patients despite the fact that the patient spends brief time $(4-6 \mathrm{hrs})$ of his hospital stay in the OR.

Paediatric cardiac surgery is most susceptible to errors $[8,9]$ due to the involvement of multiple specialities, 
changing plans and concurrent tasks. In addition, paediatric cardiac surgery requires coordinated efforts by multiple individuals, it is complex, require sophisticated equipment and structures and also require technical skills and cognitive function. Major events are more likely to occur in these complex and lengthy surgeries. While minor events are independent of complexity of cases and occurs in all type of cases [10]. Minor events are usually caused by miscommunication and distraction. Training of whole team regarding communication may help.

Minor incidents are commonly under reported because the reporting person is not aware of the importance or he/she may be too busy in the management of complex procedure. Lack of motivation and lack of knowledge about the importance of this quality assurance tool is another factor which leads to under reporting. Near misses [11] should be focused in incident reporting system to develop strategies for improvement and reduced the risk of actual patient harm. Several studies have shown that near misses occur more frequently than actual errors or adverse events. Our audit also demonstrates that the percentage of minor incidences is also high. Incident reporting should be non punative, voluntary, anonymous and confidential.

Majority of the incidents in our study are related to cardiovascular system. Higher incidence of carotid puncture and difficult intravenous and invasive lines was seen in our patients. The reason for this high incidence was probably due to inexperienced and lack of skills as first attempt in most of the cases was made by the resident or junior medical officers. We included difficult IV and Invasive lines as an adverse event because these incidents have potential for hypothermia, and increase LOS in the OR. Cardiac arrest is also seen in few patients and all reverted to spontaneous circulation. According to perioperative cardiac arrest reporting [12] (POCA) 34\% of all cardiac arrests occurred in patients with CHD and most of which having surgeries in general ORs. Mortality after cardiac arrest in CHD patients was also higher $33 \%$ vs $23 \%$.

Operating room is potentially a high risk area for medication errors [13] because only anaesthetists are responsible for administering medications and bypassing the mechanism of double checking in the wards and ICU by nurses, pharmacist, physician and computer. But due to under reporting by anaesthetists the incidence reported in different studies and in present study as well is low. In other areas nurses are more vigilant and enthusiastic in reporting errors. Overdosage was the main adverse pharmacological event in our patients. Inaccurate entry in the Graseby pumps by anaesthetists was accounting for these events. In another incident Sildenafil which was supposed to be given by NG tube was administered intravenously by a resident due to miscommunication. Fortu- nately the patients were on bypass at that time and it was given through femoral CVP. We think that most of the particles were drain by RA cannula into reservoir and then filtered out by arterial filter. Operating room is a proved to be a high risk area for adverse events. In a recent study, only $24 \%$ of OR errors were medication related compared with $17 \%$ in non OR.

Airway and pulmonary events are important for the anaesthetists. Most of these events were avoidable with extra attention and following general guidelines and policies. Change of endotracheal tubes due to smaller size tube is a common error in paediatric patients but these was only one case reported in our study. We think this

Table 4. Factors, suggestions and preventions of incident.

\begin{tabular}{ccc}
\hline Variables & Frequency Percentage \\
\hline Incident related to $(\mathbf{n}=\mathbf{3 7})$ & 30 & $81.1 \%$ \\
Anaesthesia & 02 & $5.4 \%$ \\
Patient's pre-existing condition & 05 & $13.5 \%$ \\
Others & & \\
Pactors responsible for Incident $(\mathbf{n}=\mathbf{4 6})$ & 7 & $15.2 \%$ \\
Equipment Failure & 2 & $4.3 \%$ \\
Human Factors & 34 & $73.9 \%$ \\
Others & 3 & $6.5 \%$
\end{tabular}

Suggestion for prevention $(n=46)$

Additional monitoring or material

Improved monitoring or material

Better maintenance of existing monitoring/equipment

Improved arrangement of drugs

Better training/education

Better working conditions better organization

Better supervision

Better communication

Others(describe)

Better training/education + Better supervision

Better supervision + Better

communication + Better quality

Was the incident preventable? $(n=47)$

Probably preventable with current resource

Possibly preventable with reasonable extra resources

Not obviously preventable by any change in practice

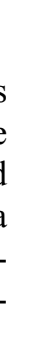


has been under reported and this needs to be emphasize in group meetings [14].

Equipment related errors [15] are high in cardiac anaesthesia in comparison to non cardiac group (37\% vs $9 \%$ ). Very low incidence of equipment failure leading to monitoring errors in our study is also due to under reporting. ECG monitoring problem is very common in paediatric cardiac surgery but we no such incident is mentioned in any patient. Anaesthetists unusually avoid mentioning such minor but incidences which could have caused disastrous results.

Human error was the major responsible for the events in our study (Table 4). These events were of minor nature. Factors like judgement errors, lack of experience and skills and miscommunication were identified. Most of the invasive lines were started by junior residents in paediatric CHD patients. These were closely supervised by the consultants but still we have seen higher incidence of carotid puncture and delays in inserting invasive lines. Human factors includes error of judgement, failure to check, technical failure of skills, lack of care, inexperience, inattention or delusion, communication and teaching.

Chance of error correction is usually possible in prebypass period but correction is difficult during bypass and post bypass period. Present audit has also shown that most of the major incidents occurred during this time, which in few cases led to major physiological derangement and morbidities.

\section{Conclusion}

Present article provides support for the idea of implementing Incident reporting as a quality assurance tool in developing countries as well. It is cheap, feasible and helps in identifying areas which need improvement. On the basis of these findings, we can develop quality improvement guidelines to enhance patient safety.

\section{REFERENCES}

[1] J. B. Cooper, R. S. Newbower, C. D. Long and B. McPeek, "Preventable Anesthesia Mishaps: A Study of Human Factors," Anesthesiology, Vol. 49, No. 6, 1978, pp. 399-406.

http://dx.doi.org/10.1097/00000542-197812000-00004

[2] A. A. Gawande, M. J. Zinner, D. M. Studdert and T. A. Brennan, "Analysis of Errors Reported by Surgeons at Three Teaching Hospitals," Surgery, Vol. 133, No. 6, 2003, pp. 614-621. http://dx.doi.org/10.1067/msy.2003.169

[3] L. Homsted, "Institute of Medicine Report: To Err Is Human: Building a Safer Health Care System," The Florida Nurse, Vol. 48, No. 1, 2000, p. 6.

[4] P. Sirivararom, T. Virankabutra, N. Hungsawanich, P. Premsamran and W. Sriraj, "The Thai Anesthesia Inci- dents Monitoring Study (Thai AIMS) of Adverse Events after Spinal Anesthesia: An Analysis of 1996 Incident Reports," Journal of the Medical Association of Thailand, Vol. 92, No. 8, 2009, pp. 1033-1039.

[5] E. A. Martinez, J. A. Marsteller, D. A. Thompson, et al., "The Society of Cardiovascular Anesthesiologists' FOCUS Initiative: Locating Errors through Networked Surveillance (LENS) Project Vision," Anesthesia \& Analgesia, Vol. 110, No. 2, 2010, pp. 307-311.

http://dx.doi.org/10.1213/ANE.0b013e3181c92b9c

[6] E. A. Martinez, A. Shore, E. Colantuoni, et al., "Cardiac Surgery Errors: Results from the UK National Reporting and Learning System," International Journal for Quality in Health Care, Vol. 23, No. 2, 2011, pp. 151-158.

[7] D. W. Bates, D. J. Cullen, N. Laird, et al., "Incidence of Adverse Drug Events and Potential Adverse Drug Events, Implications for Prevention. ADE Prevention Study Group," The Journal of the American Medical Association, Vol. 274, No. 1, 1995, pp. 29-34.

[8] P. Barach, J. K. Johnson, A. Ahmad, et al., "A Prospective Observational Study of Human Factors, Adverse Events, and Patient Outcomes in Surgery for Pediatric Cardiac Disease," The Journal of Thoracic and Cardiovascular Surgery, Vol. 136, No. 6, 2008, pp. 1422-1428.

[9] S. K. R. Catchpole, A. E. Giddings, M. R. de Leval, et al., "Identification of Systems Failures in Successful Paediatric Cardiac Surgery," Ergonomics, Vol. 49, No. 5-6, 2006, pp. 567-588. http://dx.doi.org/10.1080/00140130600568865

[10] R. P. Mahajan, "Critical Incident Reporting and Learning," The British Journal of Anaesthesia, Vol. 105, No. 1, 2010, pp. 69-75. http://dx.doi.org/10.1093/bja/aeq133

[11] M. Ricci, A. P. Goldman, M. R. de Leval, G. A. Cohen, F. Devaney and J. Carthey, "Pitfalls of Adverse Event Reporting in Paediatric Cardiac Intensive Care," Archives of Disease in Childhood, Vol. 89, No. 9, 2004, pp. 856-859. http://dx.doi.org/10.1136/adc.2003.040154

[12] J. M. Steven, "Congenital Heart Disease and Anesthesia-Related Cardiac Arrest: Connecting the Dots," Anesthesia \& Analgesia, Vol. 110, No. 5, 2010, pp. 1255-1256. http://dx.doi.org/10.1213/ANE.0b013e3181d7c059

[13] A. D. Paix, M. F. Bullock, W. B. Runciman and J. A. Williamson, "Crisis Management during Anaesthesia: Problems Associated with Drug Administration during Anaesthesia," Quality \& Safety in Health Care, Vol. 14, No. 3, 2005, p. E15. http://dx.doi.org/10.1136/qshc.2002.004119

[14] R. Maaloe, M. la Cour, A. Hansen, et al., "Scrutinizing Incident Reporting in Anaesthesia: Why Is an Incident Perceived as Critical?" Acta Anaesthesiologica Scandinavica, Vol. 50, No. 8, 2006, pp. 1005-1013. http://dx.doi.org/10.1111/j.1399-6576.2006.01092.x

[15] M. Chakravarthy, "Errors in Cardiac Anesthesia-A Deterrent to Patient Safety," Annals of Cardiac Anaesthesia, Vol. 13, No. 2, 2010, pp. 87-88. http://dx.doi.org/10.4103/0971-9784.62925 